\title{
UTILIZAÇÃO DE REJEITO DE CAULIM AMAZÔNICO COMO MATÉRIA-PRIMA NA SÍNTESE DE ZEÓLITA DO TIPO FAUJASITA
}

\author{
C. A. F. ROCHA JUNIOR ${ }^{1}$, R. F. NEVES ${ }^{1,2}$ e R. S. ANGÉLICA ${ }^{1}$ \\ ${ }^{1}$ Universidade Federal do Pará, Programa de Pós-Graduação em geologia e Geoquímica- \\ UFPA \\ ${ }^{2}$ Universidade Federal do Pará, Programa de Pós-graduação em Engenharia Química-UFPA \\ augustorocha2@gmail.com
}

\begin{abstract}
RESUMO - Este trabalho objetiva a síntese de zeólita faujasita, a partir de um rejeito do beneficiamento de caulim (caulim flint), utilizando o planejamento composto central rotacional (PCCR), para avaliar as melhores condições reacionais. Para a caracterização do caulim e dos produtos de síntese foram utilizados métodos químicos e mineralógicos. Os ensaios de síntese foram realizados modificando-se 4 variáveis reacionais: relação $\mathrm{Si} / \mathrm{Al}, \mathrm{H}_{2} \mathrm{O} / \mathrm{Na}_{2} \mathrm{O}$, tempo e temperatura, cada uma em 5 níveis diferentes. Os resultados da caracterização do caulim demonstram o potencial de utilização deste como matéria-prima para a síntese de zeólita, pois apresenta um elevado percentual de $\mathrm{SiO}_{2}$ e $\mathrm{Al}_{2} \mathrm{O}_{3}$ e fases mineralógicas bem definidas. Análises de DRX dos produtos reacionais mostraram a formação de zeólita faujasita como uma única fase mineralógica em 8 pontos (condições) do planejamento estatístico. Assim observou-se uma promissora utilização do rejeito de caulim estudado como matéria prima zeolítica.
\end{abstract}

\section{INTRODUÇÃO}

No âmbito mundial quanto a produção de caulim, o Brasil segundo o último Sumário Mineral 2013 do Departamento Nacional de Produção Mineral (DNPM) ocupa a $5^{\circ}$ posição, ficando atrás dos Estados unidos, Uzbequistão, Alemanha e República Tcheca. No cenário nacional, o estado do Pará teve a maior participação quanto a produção, aproximadamente $70 \%$ da produção interna. Este percentual se deve principalmente a duas minerados instaladas no estado a Imerys Rio Capim Caulim S/A-IRCC e a Pará Pigmentos S/A-PPSA, que são consideradas as maiores do país (Soeiro, 2014).

A importância destas duas empresas para a economia estadual e nacional é notória. Porém, a grande quantidade de resíduos gerados durante o processo de beneficiamento do caulim é bastante preocupante, uma vez que extensas lagoas de sedimentação são construídas para o acondicionamento destes rejeitos.

Estas construções demandam grandes áreas desmatadas o que altera o ecossistema local. Para minimizar os impactos ambientais causados pelos resíduos da industrial do caulim, vários trabalhos foram desenvolvidos a fim de aproveitar estes materiais em diversos processos tecnológicos, por exemplo, na produção de zeólitas (Saldanha, 2007; Maia et al., 2007, 2008 e 
2011; Moraes, 2008; Paz et al., 2010; Paz, 2008; Moraes, 2010; Menezes, 2010; Silva, 2010, Santos, 2011 e Hildebrando et al., 2012).

Zeólitas são aluminossílicatos hidratados cristalinos com elementos do grupo I e II da tabela periódica. Sua estrutura está baseada em infinitas redes tridimensionais de tetraedros de $\left[\mathrm{SiO}_{4}\right]^{4-}$ e $\left[\mathrm{AlO}_{4}\right]^{5-}$ unidos pelos vértices por oxigênio. Estas redes formam uma grande quantidade de espaços vazios e abertos, sendo estas responsáveis pela definição de inúmeras propriedades especiais das zeólitas. A substituição de $\mathrm{Si}^{4+}$ por $\mathrm{Al}^{3+}$ nos tetraedros explica a carga negativa da estrutura, o que gera uma alta capacidade de troca iônica quando os poros e canais permitem o acesso dos cátions (Breck, 1974). Como consequência desta peculiar estrutura das zeólitas, estas podem ser usadas em uma ampla faixa de aplicações industriais como material para troca iônica, adsorvente, catalisador, dentre outras, todas baseadas em sua seletividade eletrônica (Umaña, 2002).

A composição química dos resíduos cauliníticos gerados nas indústrias de papel tem uma grande semelhança ao material vulcânico precursor das zeólitas naturais. Esta particularidade vem sendo explorada no desenvolvimento de experimentos envolvendo a síntese de zeólitas a partir desta matéria-prima. De acordo com Breck (1974) a diversificação dos tipos de zeólitas obtidas a partir do caulim, depende em parte do tratamento térmico deste material, pois sem esse tratamento os produtos de síntese são feldspatóides hidratados e hidroxisodalita. Porém, com a ativação térmica é possível a obtenção de inúmeros tipos de zeólitas como: zeólita $\mathrm{X}, \mathrm{Y}$, A, P, S, L, K-F, D, W, Ba-N, Ba-M entre outras.

A utilização de zeólitas X e Y em processos de adsorção vem ao longo dos anos tomando grande força, principalmente por incentivos globais como, os créditos de carbono para a redução de gases estufa. Vários estudos vêm sendo desenvolvidos para a utilização de zeólitas $\mathrm{X}$ e Y como adsorvente de $\mathrm{CO}_{2}$, um dos principais gases causadores do aquecimento global. Portanto, a utilização de matérias primas de baixo custo, por exemplo, o resíduo caulinítico no processo de síntese de zeólita X e Y torna-se bastante atrativa, pois gera desta forma um produto com alta demanda e alto valor comercial.

Tomando como base as questões descritas acima, este trabalho tem como objetivo a utilização de caulim duro (CD), um resíduo do beneficiamento do caulim, para a síntese de zeólita do tipo faujasita, utilizando um planejamento estatístico para maximizar este processo de síntese.

\section{MATERIAIS E MÉTODOS}

\subsection{Difração de Raios-X (DRX)}

Para a análise mineralógica através de Difração de Raios-X, houve uma prévia pulverização de cada uma das amostras em um gral de ágata, sendo posteriormente transferido para portas-amostra de aço inox, utilizados como suporte na análise de DRX. As análises foram realizadas em Difratômetro de raios-x modelo X'PERT PRO MPD (PW 3040/60) da PANalytical, com Goniômetro PW3050/60 (Theta/Theta), tubo de raios-x cerâmico de anodo de $\mathrm{Cu}\left(\mathrm{K} \alpha_{1}=1,540598 \AA\right)$. A faixa angular de varredura utilizada foi entre $4^{\circ}$ a $75^{\circ}(2 \Theta)$, voltagem de $40 \mathrm{kV}$ e corrente de $30 \mathrm{~mA}$; tamanho do passo de $0,02^{\circ}(2 \theta)$, e tempo/passo de $20 \mathrm{~s}$, fenda divergente de $1 / 4^{\circ}$, máscara de $10 \mathrm{~mm}$ e spinning com $1 \mathrm{rps}$. 


\subsection{Espectrometria de Fluorescência de Raios-X (FRX)}

As composições químicas de cada caulim foram obtidos por Espectrometria de Fluorescência de Raios-X, utilizando-se um espectrômetro seqüencial Axios Minerals da PANalytical. Para cada uma das análises foi feito um disco de vidro com aproximadamente $1 \mathrm{~g}$ de cada amostra e $8 \mathrm{~g}$ do fundente tetraborato de lítio $\left(\mathrm{Li}_{2} \mathrm{~B}_{4} \mathrm{O}_{7}\right)$.

\subsection{Microscopia Eletrônica de Varredura (MEV)}

As análises de Microscopia Eletrônica de Varredura (MEV) foram realizadas em um microscópio Zeiss modelo LEO 1430. A metalização das amostras foi feita com equipamento Emitech K550, a uma pressão de $2.10^{-1}$ mbar, e corrente de $25 \mathrm{~mA}$ durante 02 '30', utilizando a platina como metalizante. As imagens foram geradas por elétrons secundários com voltagens de $20 \mathrm{kV}$, e registrados em alta resolução.

\subsection{Análise Granulométrica}

Para a análise granulométrica utilizou-se o equipamento Laser Particle Sizer analysette 22 da FritschGmbH, bem como o software MaScontrol também da FritschGmbH para a aquisição dos dados e geração do gráfico de distribuição granulométrica.

\subsection{Análise Térmica Diferencial e Gravimétrica (ATD E TG)}

O equipamento modelo $P L$ Thermal Sciences, com analisador térmico simultâneo STA 1000/1500 da Stanton Redcroft Ltda, foi utilizado nas análises Térmicas Diferenciais e Gravimétricas. As amostras foram submetidas a uma varredura de temperatura desde a ambiente até $1100^{\circ} \mathrm{C}$, com uma taxa de aquecimento de $20^{\circ} \mathrm{C} / \mathrm{min}$, sob atmosfera estática.

\subsection{Caulim}

O caulim utilizado neste trabalho é um rejeito do processo de beneficiamento do caulim para a indústria do papel, este denominado de caulim flint ou duro.

Previamente a zeolitização do caulim duro foi realizado uma calcinação deste material a uma temperatura de $600^{\circ} \mathrm{C}$ por $2 \mathrm{~h}$, esta realizada a fim de aumentar a sua reatividade no processo de síntese da zeólita faujasita.

\subsection{Tratamento do Caulim Duro (Extração de Ferro)}

A metodologia de extração de ferro a partir do caulim duro foi realizada segundo a metodologia de Mehra e Jackson (1960).

\subsection{Processo de Síntese Zeolítica}

Na síntese de zeólita do tipo faujasita utilizou-se como fonte de silício e alumínio o caulim duro ou flint (CD) tratado pelo método de Mehar e Jackson (1960) e calcinado a $600^{\circ} \mathrm{C}$. 
Também utilizou-se água destilada, metassilicato de sódio sólido $\left(\mathrm{Na}_{2} \mathrm{SiO}_{3}\right)$ e hidróxido de sódio sólido $(\mathrm{NaOH})$, sendo estes acondicionados em reatores de aço inox.

O metassilicato foi empregado para modificar a relação $\mathrm{Si} / \mathrm{Al}$ e em conjunto com o hidróxido fornecer sódio para formação da zeólita. As relações de $\mathrm{Si} / \mathrm{Al}, \mathrm{H}_{2} \mathrm{O} / \mathrm{Na}_{2} \mathrm{O}$, tempo e temperatura de síntese foram determinadas a partir de um planejamento experimental denominado planejamento composto central rotacional (PCCR) (Tabela 1) tomando como base os resultados de Rocha Junior (2012) que sintetizou zeólita faujasita a partir de diferentes caulins. Tal planejamento foi utilizado para buscar otimizar os resultados obtidos para o caulim duro.

Tabela 1- Planejamento experimental para a zeolítização do CD tratado.

\begin{tabular}{|c|c|c|c|c|}
\hline Pontos & $\mathbf{S i} / \mathbf{A l}$ & Tempo (h) & Temperatura $\left({ }^{\circ} \mathrm{C}\right)$ & $\mathrm{H}_{2} \mathrm{O} / \mathrm{Na}_{2} \mathrm{O}$ \\
\hline 1 & 2 & 7 & 100 & 40 \\
\hline 2 & 3 & 7 & 100 & 40 \\
\hline 3 & 2 & 13 & 100 & 40 \\
\hline 4 & 3 & 13 & 100 & 40 \\
\hline 5 & 2 & 7 & 120 & 40 \\
\hline 6 & 3 & 7 & 120 & 40 \\
\hline 7 & 2 & 13 & 120 & 40 \\
\hline 8 & 3 & 13 & 120 & 40 \\
\hline 9 & 2 & 7 & 100 & 80 \\
\hline 10 & 3 & 7 & 100 & 80 \\
\hline 11 & 2 & 13 & 100 & 80 \\
\hline 12 & 3 & 13 & 100 & 80 \\
\hline 13 & 2 & 7 & 120 & 80 \\
\hline 14 & 3 & 7 & 120 & 80 \\
\hline 15 & 2 & 13 & 120 & 80 \\
\hline 16 & 3 & 13 & 120 & 80 \\
\hline 17 & 1,5 & 10 & 110 & 60 \\
\hline 18 & 3,5 & 10 & 110 & 60 \\
\hline 19 & 2,5 & 4 & 110 & 60 \\
\hline 20 & 2,5 & 16 & 110 & 60 \\
\hline 21 & 2,5 & 10 & 90 & 60 \\
\hline 22 & 2,5 & 10 & 130 & 60 \\
\hline 23 & 2,5 & 10 & 110 & 20 \\
\hline 24 & 2,5 & 10 & 110 & 100 \\
\hline 25 & 2,5 & 10 & 110 & 60 \\
\hline 26 & 2,5 & 10 & 110 & 60 \\
\hline 27 & 2,5 & 10 & 110 & 60 \\
\hline 28 & 2,5 & 10 & 110 & 60 \\
\hline 29 & 2,5 & 10 & 110 & 60 \\
\hline 30 & 2,5 & 10 & 110 & 60 \\
\hline 31 & 2,5 & 10 & 110 & 60 \\
\hline 32 & 2,5 & 10 & 110 & 60 \\
\hline
\end{tabular}




\section{RESULTADOS E DISCUSSÕES}

\subsection{Caulim}

Análise de difração de raios-x: A partir da análise de difração na Figura 1, podemos observar que o caulim CD é constituido principalmente pelo argilomineral caulinita $(\mathrm{K})$, seguido por outras fases mineralogicas como quartzo (Q), anatásio $(A)$ e hematita $(\mathrm{H})$. Estudos de Carneiro et al. (2003) com caulim CD da mesma região, também reportaram as mesmas fases mineralogicas.

Na Figura 2 podemos observar a análise de DRX do CD após o processo de calcinação a $600^{\circ} \mathrm{C}$ por $2 \mathrm{~h}$. Nesta nota-se uma total destruição da estrutura da cauliníta, evidenciada pelo desaparecimento dos seus picos caracteristicos. Este colapso estrutural está associado ao seu processo de desidroxilação entre 450 e $600^{\circ} \mathrm{C}$ formando um material amorfo denominado de metacaulim (Souza Santos, 1989). Os picos de quartzo, anatásio e hematita mesmo após a calcinação ainda são observados, pois os mesmos apresentam estruturas resistentes a temperatura utilizada para a calcinação.

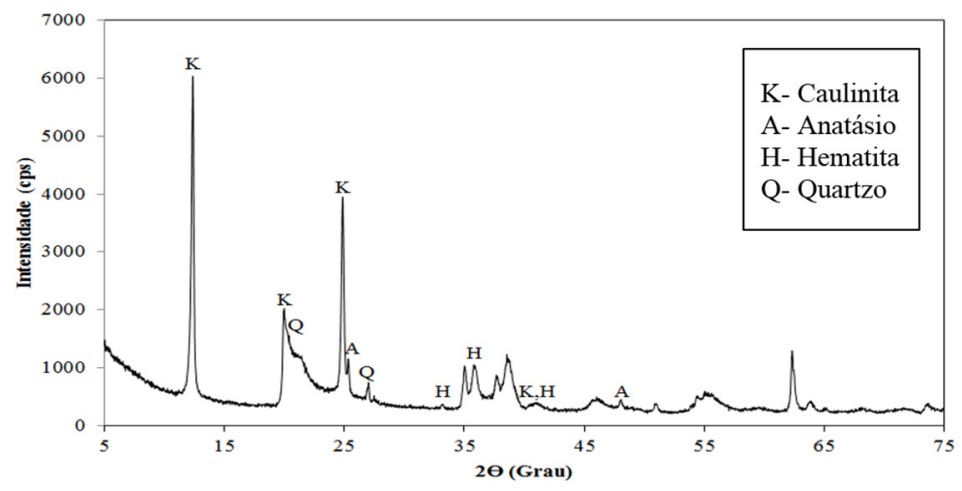

Figura 1- Difração de Raios-X do caulim CD

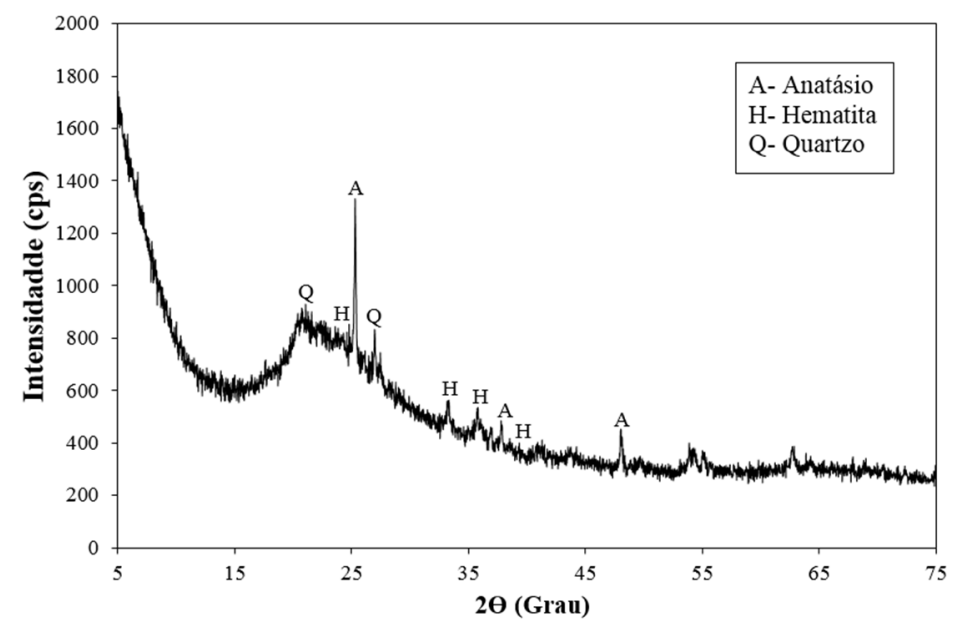

Figura 2- DRX do caulim CD calcinado a $600^{\circ} \mathrm{C}$ 
Análise química por fluorescência de raios-x: A análise química do Caulim CD é mostrada na Tabela 2. Nesta podemos observar um alto teor de óxido de Si e Al, característica favorável a síntese de zeólita, uma vez que este é constituído essencialmente por estes óxidos (Breck, 1979).

Os valores encontrados para o $\mathrm{Fe}_{2} \mathrm{O}_{3}$ e $\mathrm{TiO}_{2}$ no $\mathrm{CD}$, estão relacionados aos minerais acessórios como hematita $\left(\mathrm{Fe}_{2} \mathrm{O}_{3}\right)$ e anatásio $\left(\mathrm{TiO}_{2}\right)$, assim como fases não cristalinas de ferro e possíveis substituições isomórficas de $\mathrm{Al}^{+3}$ por $\mathrm{Fe}^{+3}$ no horizonte do caulim duro (Carneiro et al., 2003, Criscuolo, 2008).

Tabela 2- Análise química por FRX do CD.

\begin{tabular}{cc}
\hline Óxidos & $(\boldsymbol{\%})$ \\
\hline $\mathrm{SiO}_{2}$ & 43,92 \\
$\mathrm{Al}_{2} \mathrm{O}_{3}$ & 37,7 \\
$\mathrm{Fe}_{2} \mathrm{O}_{3}$ & 1,84 \\
$\mathrm{Na}_{2} \mathrm{O}$ & $<0,01$ \\
$\mathrm{TiO}_{2}$ & 2,05 \\
$\mathrm{ZrO}_{2}$ & 0,15 \\
$\mathrm{PF}$ & 14,3 \\
\hline
\end{tabular}

Análise granulométrica: Na distribuição granulométrica do CD na forma in natura (figura 3), nota-se uma ampla faixa de distribuição de partículas, desde 0,04 a $125 \mu \mathrm{m}$, bem como a presença de duas modas, caracterizando este material como bastante heterogêneo.

Segundo Souza Santos (1989) e Souza (2000) partículas de caulinita no caulim CD apresentam granulometria extremamente fina, que aglomeram formando corpos maiores e bastante densos que não se dispersam facilmente em água e apresentam uma grande resistência mecânica. Esta característica leva a uma ampla faixa de granulometria, como observado na Figura 3.

A calcinação realizada no caulim CD causou uma sinterização e/ou aglomeração das frações mais finas $(<5 \mu \mathrm{m})$ deslocando tais partículas para valores maiores de granulometria, como podemos ver na Figura 4.

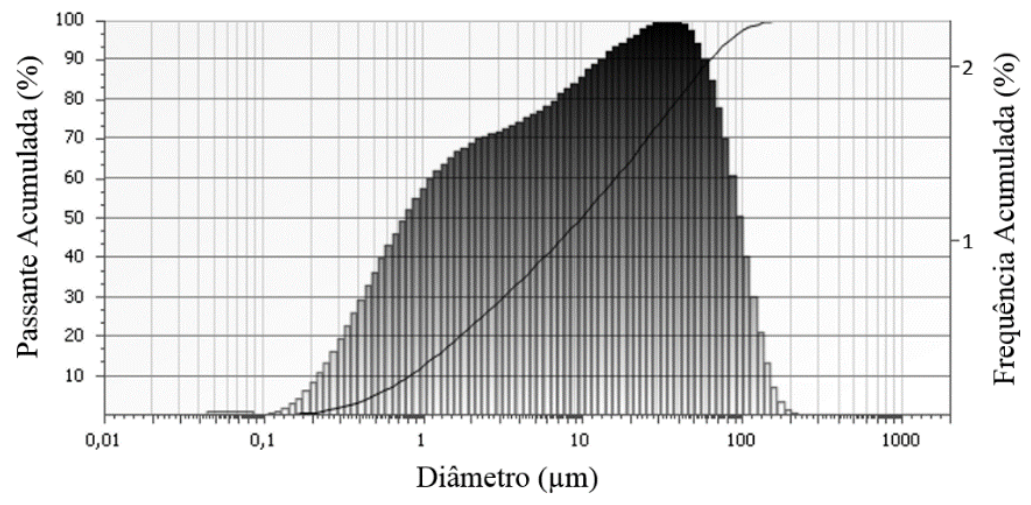

Figura 3- Análise granulométrica do caulim CD 


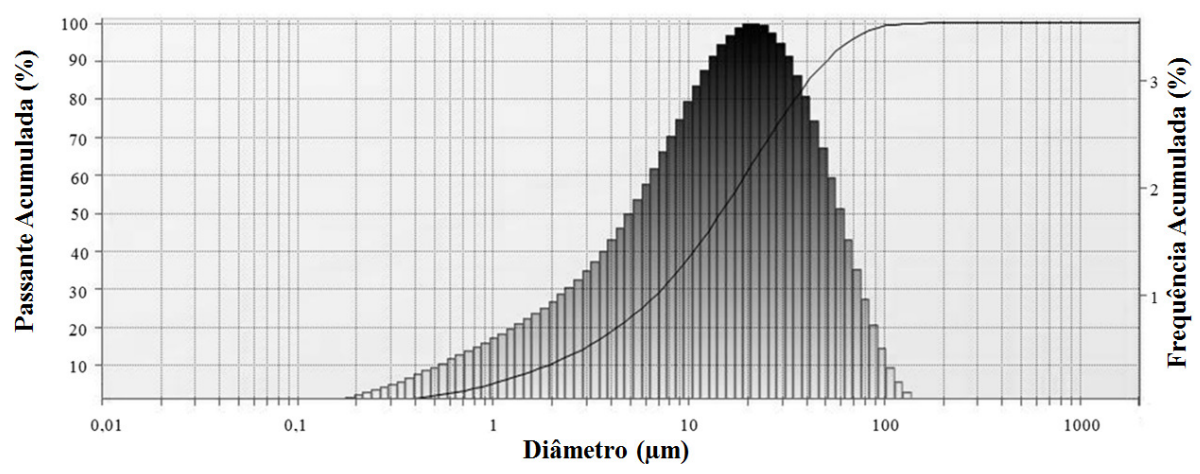

Figura 4- Análise granulométrica do caulim CD calcinado a $600^{\circ} \mathrm{C}$

\subsection{Zeólita}

A Figura 5 mostra os resultados de difração de raios-x de alguns pontos do planejamento experimental. Nesta, observar-se uma região ótima quanto a formação de zeólita faujasita, composta por 8 pontos. Fora desta região há formação significativa de outras fases zeolíticas como A, P e sodalita, como mostra o ponto 18.

Dentro da região ótima do planejamento, nos pontos $21\left(90^{\circ} \mathrm{C}\right), 9,10,11$ e $12\left(100^{\circ} \mathrm{C}\right)$ podemos notar uma elevação na intensidade dos picos da zeólita $\mathrm{Y}$, que de acordo com Qiang et al. (2010) está ligada ao aumento da cristalinidade desta fase zeolítica, frente a elevação de temperatura de 90 para $100^{\circ} \mathrm{C}$. Ainda segundo o trabalho de Qiang et al. (2010) temperaturas de $110^{\circ} \mathrm{C}$ e $120^{\circ} \mathrm{C}$ favoreceriam a diminuição desta cristalinidade, porém os pontos obtidos dentro e fora da região ótima (pontos 24 e $18\left(110^{\circ} \mathrm{C}\right)$ e 14 e $\left.13\left(120^{\circ} \mathrm{C}\right)\right)$ não seguiram o mesmo padrão. Este aumento pode estar ligado a combinação da temperatura com as outras variáveis reacionais adotadas no planejamento estatístico.

Uma outra análise bastante importante que podemos fazer através da Figura 5, está relacionada ao tempo mínimo de síntese da zeólita do tipo faujasita. Dentro da região ótima foram obtidos produtos zeolíticos com tempos de 7 e $10 \mathrm{~h}$ (pontos 9, 10, 13, 14, 18, 21 e 24), que em contraste com trabalhos de Hildebrando et al. (2012) e Rocha Junior (2012), são resultados bastante promissores, uma vez que estes reportam sínteses com tempo reacional de 48 e 13h, respectivamente. Embora Hildebrando et al. (2012) e Rocha Junior (2012) tenham utilizado caulins da mesma região que o caulim CD empregado neste trabalho, os mesmos investigaram quantidades de variáveis e níveis reacionais abaixo do número utilizado para as sínteses realizadas neste trabalho. Esta maior quantidade de pontos estatísticos foi fundamental para a investigação de um maior número de zonas reacionais e obtenção de zonas ótimas. 


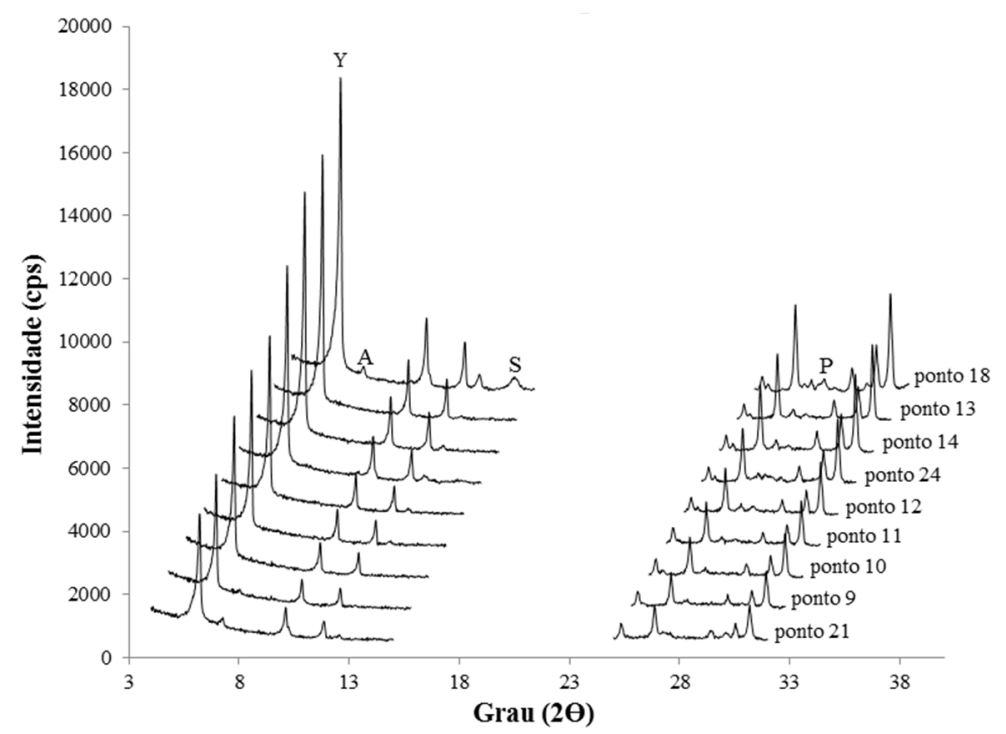

Figura 5- Pontos do planejamento estatístico.

Análise quimica: Na tabela 3 estão dispostos as análises químicas dos pontos presentes na região ótima do planejamento estatístico. Das oito relação de $\mathrm{Si} / \mathrm{Al}$ encontradas para estes pontos, sete encontram-se abaixo da região esperada para a zeolita faujasita do tipo Y, que de acordo com Breck (1974) está entre 1,5 e 3. Como as relações foram determinadas a partir da Fluorescência de Raios-X, não foi possível separar os percentuais de Si e Al na zeolita Y e material amorfo (metacaulim não reagido), uma vez que esta análise leva em consideração o material como um todo, assim esses valores de $\mathrm{Si} / \mathrm{Al}$ encontrados para cada ponto podem ter sofrido uma diminuição pela inserção da fase amorfa.

O percentual de óxido de ferro encontrado nos produtos zeolíticos (tabela 3) está relacionado ao ferro encontrado no caulim CD. Como podemos observar houve uma redução do valor inicial no caulim $(1,84 \%)$ para valores próximos a $0,40 \%$ como podemos ver na Tabela 3. Esta redução está intimamente ligada ao processo de extração do ferro aplicada ao caulim $\mathrm{CD}$, realizada para minimizar o efeito deste metal durante a síntese zeolítica, uma vez que Rocha Junior (2012) demonstrou um efeito negativo do ferro para sínteses com relações de $\mathrm{Si} / \mathrm{Al}$ próximas a 2 a partir deste caulim.

A presença de $\mathrm{TiO}_{2}$ no produto zeolítico apresentado na Tabela 3, relaciona-se ao mineral acessório anatásio presente inicialmente no caulim $\mathrm{CD}$. 
Tabela 3- Análise química da região ótima do planejamento estatístico.

\begin{tabular}{cccccccc}
\hline $\begin{array}{c}\text { Ponto do } \\
\text { Planejamento }\end{array}$ & $\begin{array}{c}\mathrm{Al}_{2} \mathrm{O}_{3} \\
(\%)\end{array}$ & $\mathrm{SiO}_{2}(\%)$ & $\mathrm{Si} / \mathrm{Al}$ & $\mathrm{Fe}_{2} \mathrm{O}_{3}(\%)$ & $\mathrm{Na}_{2} \mathrm{O}(\%)$ & $\begin{array}{c}\mathrm{TiO}_{2} \\
(\%)\end{array}$ & $\begin{array}{c}\text { Perda ao } \\
\text { fogo }(\%)\end{array}$ \\
\hline 13 & 25,74 & 39,9 & 1,32 & 0,41 & 14,49 & 1,32 & 18,14 \\
14 & 24,19 & 43,15 & 1,51 & 0,42 & 13,21 & 1,43 & 17,61 \\
24 & 23,23 & 39,95 & 1,46 & 0,35 & 14,81 & 1,33 & 20,33 \\
21 & 25,30 & 39,58 & 1,33 & 0,44 & 15,26 & 1,55 & 17,88 \\
12 & 25,00 & 42,42 & 1,44 & 0,43 & 12,67 & 1,47 & 18,01 \\
11 & 26,22 & 40,20 & 1,30 & 0,35 & 14,25 & 1,39 & 17,60 \\
10 & 24,78 & 40,75 & 1,40 & 0,43 & 14,35 & 1,55 & 18,14 \\
9 & 26,39 & 38,43 & 1,24 & 0,38 & 15,25 & 1,51 & 18,04 \\
\hline
\end{tabular}

Análises termogravimétricas (TG) e térmica diferenciais (ATD): Na análise térmica (Figuras 6) de dois pontos do planejamento estatístico (11 e 13) podemos observar uma continua perda de água superficial e água zeolítica na faixa de temperatura próxima a ambiente até $300^{\circ} \mathrm{C}$, evidenciada pela presença do pico endotérmico na curva térmica diferencial (ATD). Também, observa-se na Figura 6 um pico exotérmico próximo a temperatura de $880{ }^{\circ} \mathrm{C}$ para ambos os pontos do planejamento. Segundo Breck (1974) este pico é característico da zeólitas $\mathrm{Y}$, referente ao colapso estrutural desta fase mineralógica para a formação de um material amorfo.
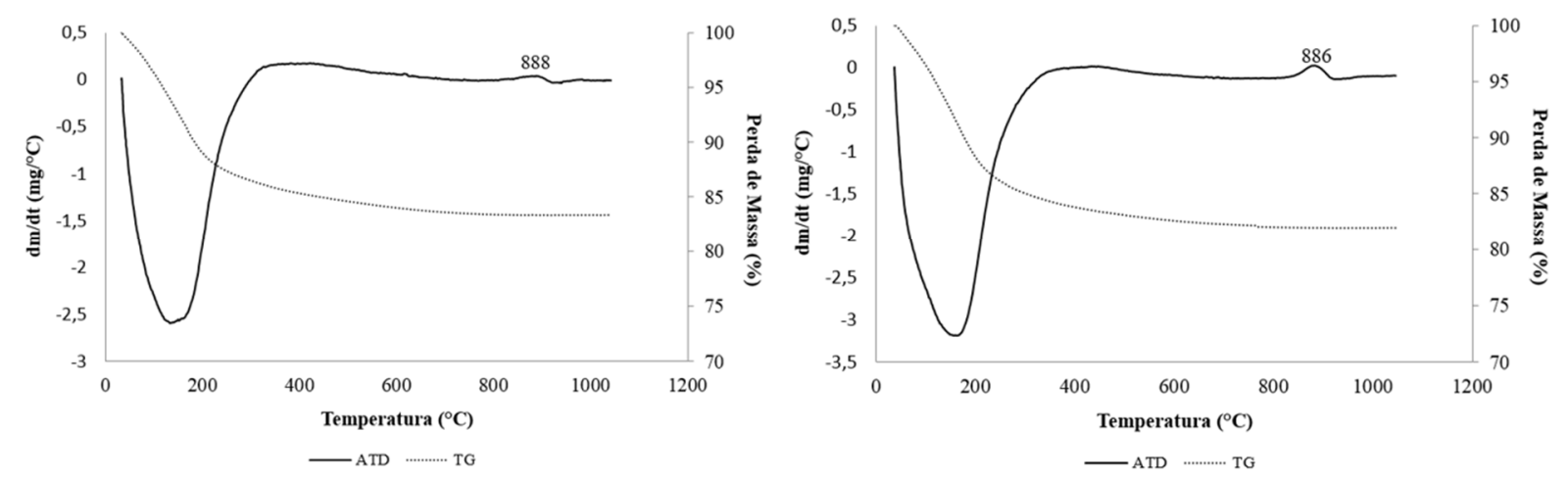

Figura 6- Análise térmica dos pontos 11 e 13 do planejamento estatístico.

Análise morfológica por microscopia eletrônica de varredura (MEV): A análise de microscopia eletrônica de alguns produtos do planejamento experimental é mostrada na Figura 7. Nestas, podemos observar cristais com morfologia octaédrica típicas de zeólita do tipo faujasita. De acordo com Covarrubias et al. (2006) esta morfologia bem definida não é comumente observada na síntese de faujasita a partir de caulim.

Na Figura 7, também podemos observar cristais esféricos de zeólita P. Segundo Liu et al. (2003) e Christidis e Papantoni (2008) essa formação em conjunto com a zeólita Y (Figura 7) está ligada a competição destas fases no meio reacional, sendo possível a formação de zeólita $\mathrm{P}$ à custa dos cristais de zeólita Y. 
A presença de zeólita $\mathrm{P}$ na microscopia não reflete uma alta concentração desta fase nos pontos 13 e 14 do planejamento, uma vez que a análise de difração não detecta esta zeólita, o que pode caracterizar esta fase zeolítica como traço.
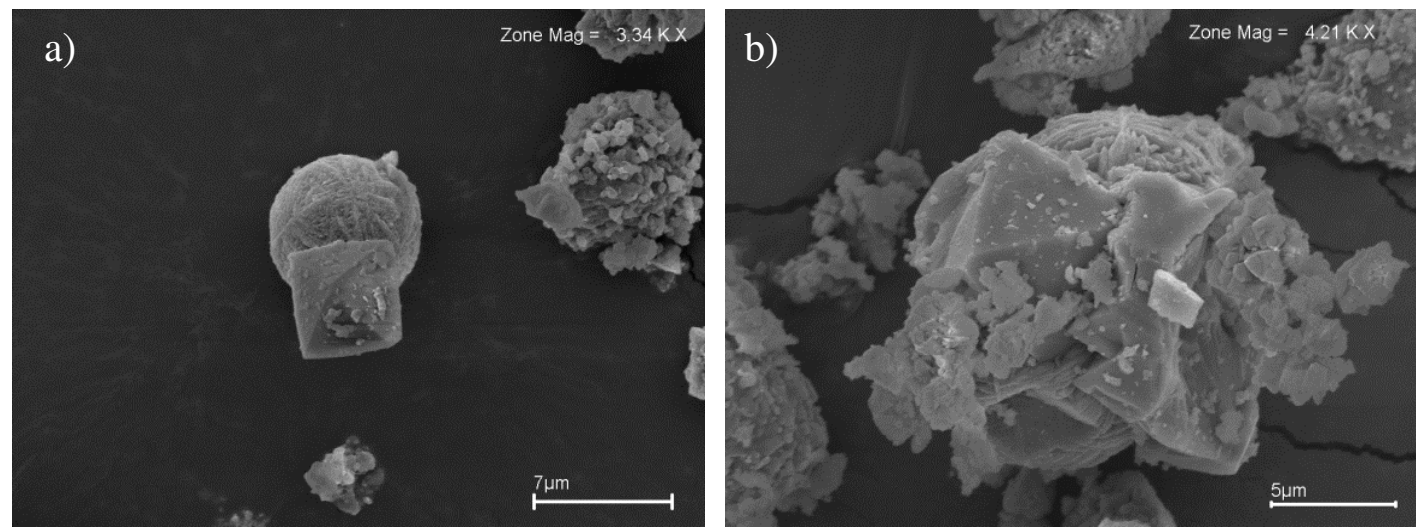

Figura 7- Fotomicrografia dos pontos 13 (a) e 14 (b) do planejamento experimental.

\section{CONCLUSÕES}

O caulim duro utilizado neste trabalho como matéria-prima para síntese de zeólita do tipo faujasita, demonstrou-se bastante promissor, uma vez que em todos os pontos do planejamento estatístico foi possível a obtenção desta zeólita.

Com o planejamento experimental foi possível a detecção de uma zona ótima com oito pontos reacionais, o que é bastante significativo, pois amplia as escolhas de condições químicas para futuros trabalhos de síntese de zeólita do tipo faujasita.

A partir da combinação das variáveis reacionais adotadas neste trabalho, foi possível a minimização dos tempos de síntese em relação a algumas pesquisas que utilizaram caulim da região amazônica como matéria-prima zeolítica.

\section{REFERÊNCIAS}

BRECK, D. W. Zeolite Molecular Sieves: Structure, Chemistry and Use. 2ed. New York: John Wiley \& Sons Inc., 1974.

CARNEIRO, B. S., ANGÉliCA, R. S., SCHELlER, T., CASTRO, E. A. S., NEVES, R. F. Caracterização mineralógica e geoquímica e estudo das transformações de fase do caulim duro da região do Rio Capim, Pará. Cerâmica, n. 49, 237-244. 2003.

CHRISTIDIS, G. E., PAPANTONI, H. Synthesis of FAU Type Zeolite Y from Natural Raw Materials: Hydrothermal SiO2-Sinter and Perlite Glass. The Open Mineralogy Journal, v.2, 1-5, 2008.

COVARRUBIAS, C., GARCÍA, R., ARRIAGADA, R., YÁNEZ, J., GARLAND, M. T., Micropor. Mesopor. Mater. 88. 220-231. 2006

CRISCUOLO, P. S. R., Beneficiamento do caulim duro das bacias dos rios Capim e Jari através do processo de agregação seletiva. 2008. 113p. Dissertação (Mestrado em Engenharia Metalúrgica e de Minas) - Universidade Federal de Minas Gerais. Belo Horizonte, 2008. 
HILDEBRANDO, E. A.; ANGÉLICA, R. S.; NEVES, R. F.; F. R. VALENZUELA-DIAZ, R. Síntese de zeólita do tipo faujasita a partir de um rejeito de caulim. Cerâmica, v. 58, nº. 348, p. 453-458, 2012.

LIU, X M., YAN, Z. F., Wang, H. P., et al. In situ synthesis of NaY zeolite with coal-based kaolin. Journal of Natural Gas Chemistry. 12(1), p. 63-70, 2003.

MAIA, A. A. B., ANGÉLICA, R. S.,NEVES, R. F. Use of industrial kaolin waste from the Brazilian Amazon region for synthesis of zeolite A. Clay Minerals, n. 46, 127-136, 2011.

MAIA, A. A. B., SALDANHA, E., ANGÉliCA, R. S., SOUZA, C. A., NEVES, R. F. Utilização de rejeito de caulim da Amazônia na síntese da zeólita A. Cerâmica, 53: 319324, 2007.

MAIA, A. A. B., SAldANHA, E., ANGÉliCA, R. S., SOUZA, C. A., NEVES, R. F. Estabilidade térmica da zeólita A sintetizada a partir de um rejeito de caulim da Amazônia. Cerâmica, 54: 345-350, 2008.

MEHRA, G. P., JACKSON, M. L. Iron Oxide Removal from Soils and Clays by a Dithionite Citrate SystemBuffered with Sodium Bicarbonate. Clay and Clay Minerals, v. 7, p.317327, (1960).

PAZ, S. P. A. Influência dos Ânions $\mathrm{OH}^{-}, \mathrm{SO}_{4}{ }^{2-}, \mathrm{CO}_{3}{ }^{2-}, \mathrm{Cl}^{-}$e $\mathrm{NO}^{3-}$ na Síntese de Zeólita A e Sodalita, a Partir de Rejeito Caulinítico via Processo Hidrotermal. Trabalho de Conclusão de Curso (Engenharia Química) Instituto de Tecnologia Universidade Federal do Pará. Belém, 2008.

PAZ, S. P. A., Angélica R. S. \& Neves R. F. Síntese hidrotermal de sodalita básica a partir de um rejeito de caulim termicamente ativado. Química Nova, 33, 579-583, 2010.

QIANG, L.; YING, Z.; ZHIJUN, C.; WEI, G.; LISHAN, C. Influence of synthesis parameters on the crystallinity and $\mathrm{Si} / \mathrm{Al}$ ratio of $\mathrm{NaY}$ zeolite synthesized from kaolin. Petroleum Science, v. 7, p. 403-409, 2010.

ROCHA JUNIOR, C. A. F. Desenvolvimento de processo para obtenção de zeólita do tipo faujasita a partir de caulim de enchimento utilizado em papel, caulim duro e tube press: aplicação como adsorvente. 2012. 94p. Qualificação de Tese (Doutorado em Geoquímica e Petrologia) Instituto de Geociências, Universidade Federal do Pará, Belém, 2012.

SALDANHA, E. Síntese e caracterização da analcima a partir de rejeito de caulim e aplicação como adsorvente. 2007. Dissertação (Mestrado em Engenharia Química) Instituto de Tecnologia Universidade Federal do Pará. Belém, 2007.

SANTOS, S. C. A. Síntese de Zeólitas A e 5A a Partir de Caulim: uma Comparação dos Métodos de Síntese Estático e Dinâmico. 2011. 112p. Dissertação (Mestrado em Geoquímica e Petrologia) Instituto de Geociências, Universidade Federal do Pará, Belém, 2011.

SILVA, L.N. Cinética da Transformação Hidrotermal de Rejeito Caulinítico em Sodalita com Base nos Dados de DRX Ex Situ. Trabalho de Conclusão de Curso (Engenharia Química) Instituto de Tecnologia Universidade Federal do Pará. Belém, 2010.

SOEIRO, E. R. Sumário Mineral 2013. Departamento Nacional de Produção Mineral. Disponível em:

https://sistemas.dnpm.gov.br/publicacao/mostra_imagem.asp?IDBancoArquivoArquivo $=8973$ > Acesso em: 05 mai. 2014.

SOUZA SANTOS, P. Ciência e tecnologia de argilas. Vol.1. São Paulo: Edgard Blucher,1989.

SOUZA, D. J. L. Caracterização geológica, mineralógica, química e física do caulim da mina da RCC- Rio Capim Caulim (PA). 116 p. Dissertação (Mestrado em Geologia e 
Petrologia) - Curso de Pós-Graduação em Geologia e Geoquímica, Centro de Geociências, Universidade Federal do Pará, Belém. 2000.

Umaña, J. C. Tese Dr, Universitat Politècnica de Catalunya, Espanha (2002). 